\title{
Manipulação segura de hortaliças: experiência extensionista em tempos de pandemia de COVID-19
}

\author{
Daniel Felipe de Oliveira Gentil ${ }^{1}$
}

\begin{abstract}
Resumo: O presente relato descreve as atividades realizadas pelos integrantes da ação curricular de extensão da Universidade Federal do Amazonas, intitulada "Manipulação segura de hortaliças", em uma comunidade de agricultores familiares de Manaus, Amazonas, no decorrer do segundo semestre de 2020. Desse modo, são apresentados os objetivos, as estratégias e os instrumentos metodológicos para o desenvolvimento da ação extensionista. As novas experiências, com o uso de tecnologias de informação e comunicação e mídias digitais, possibilitaram alcançar os objetivos propostos, mesmo com as dificuldades no acesso e no uso dessas tecnologias.
\end{abstract}

Palavras-chave: Extensão universitária. Agricultura familiar. Pós-colheita de hortaliças.

Área Temática: Trabalho. Saúde. Segurança alimentar.

\section{Safe handling of vegetables: extension experience in times of COVID-19 pandemic}

Abstract: This report describes the activities carried out by members of the extension curricular action of the Federal University of Amazonas, entitled "Safe handling of vegetables", in a community of family farmers in Manaus, Amazonas, during the second half of 2020. Thus, the objectives, strategies and methodological tools for the development of extension action are presented. New experiences, with the use of information and communication technologies and digital media, made it possible to achieve the proposed objectives, despite the difficulties in accessing and using these technologies.

Keywords: University extension. Family farming. Post-harvest of vegetables.

\section{Manejo seguro de hortalizas: experiencia de extensión en tiempos de pandemia COVID-19}

Resumen: Este informe describe las actividades realizadas por integrantes de la acción de extensión curricular de la Universidad Federal de Amazonas, titulado "Manejo seguro de hortalizas", en una comunidad de agricultores familiares en Manaus, Amazonas, durante el segundo semestre de 2020. Así, se presentan los objetivos, estrategias y herramientas metodológicas para el desarrollo de la acción de extensión. Las nuevas experiências, con el uso de las tecnologías de la información y la comunicación y los medios digitales, permitieron alcanzar los objetivos propuestos, incluso con las dificultades de acceso y uso de estas tecnologías.

Palabras clave: Extensión universitaria. Agricultura familiar. Poscosecha de hortalizas.

${ }^{1}$ Professor da Faculdade de Ciências Agrárias e Coordenador da ACE "Manipulação segura de hortaliças", da Universidade Federal do Amazonas. Av. Gal. Rodrigo O. J. Ramos, n6200, Bairro Coroado, CEP. 69080-900, Manaus, Amazonas. Telefone: (92) 99996-0947. E-mail: dfgentil@ ufam.edu.br. 


\section{INTRODUÇÃO}

Em tempos de pandemia de COVID-19, declarada oficialmente em março de 2020 pela Organização Mundial de Saúde, muitos profissionais tiveram que continuar as suas atividades, seja por essencialidade de suas funções, seja por necessidade de manutenção da renda familiar, ou por ambos os motivos. Isso não foi diferente para agricultores familiares de Manaus, Amazonas, que permaneceram comercializando os seus produtos em feiras locais ou por meio do comércio eletrônico (e-commerce).

A COVID-19 é considerada uma síndrome aguda respiratória severa (SARS), sendo que a transmissão do vírus ocorre pelo ar, por contato com secreções contaminadas (gotículas de saliva, espirro, tosse e catarro), contato pessoal (toque e aperto de mão) e por contato com superfícies e objetos contaminados (GASPAR; DOMINGUES; BARBOSA, 2020). Sendo assim, é fundamental entender de que maneira as atividades e as condições de trabalho podem contribuir para a disseminação da doença e, sobretudo, para o estabelecimento de estratégias para o enfrentamento da pandemia (DINIZ et al., 2020).

A transmissão do vírus da COVID-19 por alimentos frescos, como hortaliças, parece improvável, embora a transmissão por embalagens e superfícies de preparo, transporte e comercialização de hortaliças, não possa ser descartada. Ainda assim, outros microrganismos patogênicos e parasitas intestinais (como Ascaris lumbricoides, Entamoeba histolytica, E. coli, Escherichia coli e Giardia lamblia) podem ser transmitidos pela superfície de hortaliças e de objetos usados em seu manuseio, caso não sejam adotadas medidas adequadas na manipulação desde a colheita até o consumo (GREGÓRIO et al., 2012).

A contaminação de hortaliças pode ocorrer em várias fases das cadeias produtiva e comercial, em particular por meio de solos de cultivo, adubos orgânicos, águas de irrigação e lavagem, condições no preparo, transporte, armazenamento e exposição durante a comercialização (GREGÓRIO et al., 2012). As hortaliças herbáceas com folhas sobrepostas e superfície irregular são as que mais favorecem a retenção e sobrevivência de microrganismos patogênicos e parasitas intestinais nelas depositados, enquanto as hortaliças que apresentam superfície lisa e pequena em relação ao seu volume, como hortaliças-fruto, possuem capacidade reduzida de retenção (MAROUELLI; SILVA, 1998).

Com a pandemia de COVID-19, as universidades passaram a enfrentar desafios concernentes ao desenvolvimento das atividades acadêmicas (MÉLO et al., 2021). Desse modo, a extensão universitária teve que superar as adversidades surgidas no campo da educação, em decorrência das medidas de isolamento e distanciamento social (WOLTMANN et al., 2021), incorporando mudanças em suas metodologias com a finalidade de continuar atendendo às demandas sociais (MELO et al., 2020).

A Universidade Federal do Amazonas suspendeu as atividades acadêmicas presenciais em 16 de março de 2020. Em 17 de agosto de 2020, iniciou o ensino remoto emergencial (ERE) de forma temporária (75 dias), com mediação pedagógica assentada nas tecnologias de informação e comunicação e mídias digitais. Em dois de setembro de 2020, a Pró-Reitoria de Extensão publicou edital de seleção pública 
simplificada para ações de extensão, a serem desenvolvidas durante o período do calendário acadêmico de ERE. Uma das modalidades de extensão incluídas no edital foi o Programa de Ação Curricular Remota de Extensão. O programa é uma concessão de bolsas para docentes que desejem coordenar e executar as ações curriculares de extensão (ACE), empregando o valor recebido no desenvolvimento do projeto, que conta com participação de discentes e colaboradores (UNIVERSIDADE FEDERAL DO AMAZONAS, 2021).

Diante do exposto, foi realizada a ACE "Manipulação segura de hortaliças”, em comunidade de agricultores familiares de Manaus, Amazonas, para verificar e reforçar as medidas preventivas individuais da COVID-19 (higiene e uso de equipamentos de proteção), visando contribuir para a redução do risco de exposição ao vírus da COVID-19; e averiguar e aprimorar os cuidados nas atividades laborais (procedimentos, ambientes e utensílios), durante a colheita e pós-colheita de hortaliças, com vistas à redução/eliminação da carga patogênica e parasitária decorrentes do manuseio.

\section{OBJETIVOS}

Este relato tem como objetivo descrever as atividades realizadas pelos integrantes da ACE "Manipulação segura de hortaliças”, vinculada à Universidade Federal do Amazonas, em uma comunidade de agricultores familiares de Manaus, Amazonas.

\section{METODOLOGIA}

Trata-se de um trabalho descritivo, em forma de relato de experiência, das atividades realizadas por oito discentes e um professor do Curso de Agronomia da Universidade Federal do Amazonas, integrantes da ACE "Manipulação segura de hortaliças". A ação foi executada entre 21 de setembro e 14 de dezembro de 2020. A metodologia adotada foi baseada na pesquisa-ação, na qual os integrantes estão envolvidos de modo participativo na ação ou na resolução de um problema coletivo (THIOLLENT, 2011). O público alvo foi constituído por nove famílias de agricultores familiares (21 pessoas no total) da Comunidade do Uberê, Projeto de Assentamento “Água Branca”, Puraquequara, Zona Leste de Manaus, Amazonas.

O desenvolvimento da ação foi integralmente por modo remoto. Os encontros entre o professor (coordenador) e os discentes foram semanais, em videoconferências síncronas, por meio do serviço de comunicação Google Meet. A interlocução com os comunitários foi por meio do aplicativo multiplataforma de celular WhatsApp, uma vez que não possuem computador e/ou têm acesso precário à internet. Desse modo, a comunicação entre a equipe e os agricultores familiares foi por mensagens de texto, chamadas de voz, ligações telefônicas e envio de documentos em PDF (Portable Document Format). 


\section{RESULTADOS E DISCUSSÃO}

Inicialmente, nas primeiras semanas de execução da $\mathrm{ACE}$, ocorreu a preparação dos integrantes da equipe. O professor apresentou os conteúdos referentes à "agricultura familiar", "medidas preventivas individuais da COVID-19" e "transmissão de microrganismos patogênicos e parasitas intestinais por hortaliças", e promoveu debates sobre esses temas com os discentes, disponibilizando bibliografia para leitura prévia. Além disso, os discentes tiveram instrução em postura e etiqueta profissionais em mídias sociais, uma vez que iriam manter diálogos remotos frequentes com os agricultores familiares.

As estratégias e os instrumentos metodológicos foram concebidos coletivamente pela equipe. A abordagem foi conduzida em cinco etapas (prevenção da COVID-19; colheita; preparação para a comercialização; transporte; e comercialização das hortaliças), sendo cada etapa realizada em duas rodadas de interlocuções, ficando a primeira rodada à verificação das medidas e cuidados adotados pelos agricultores familiares, e a segunda à explanação das proposições técnicas pela equipe (Figura 1).

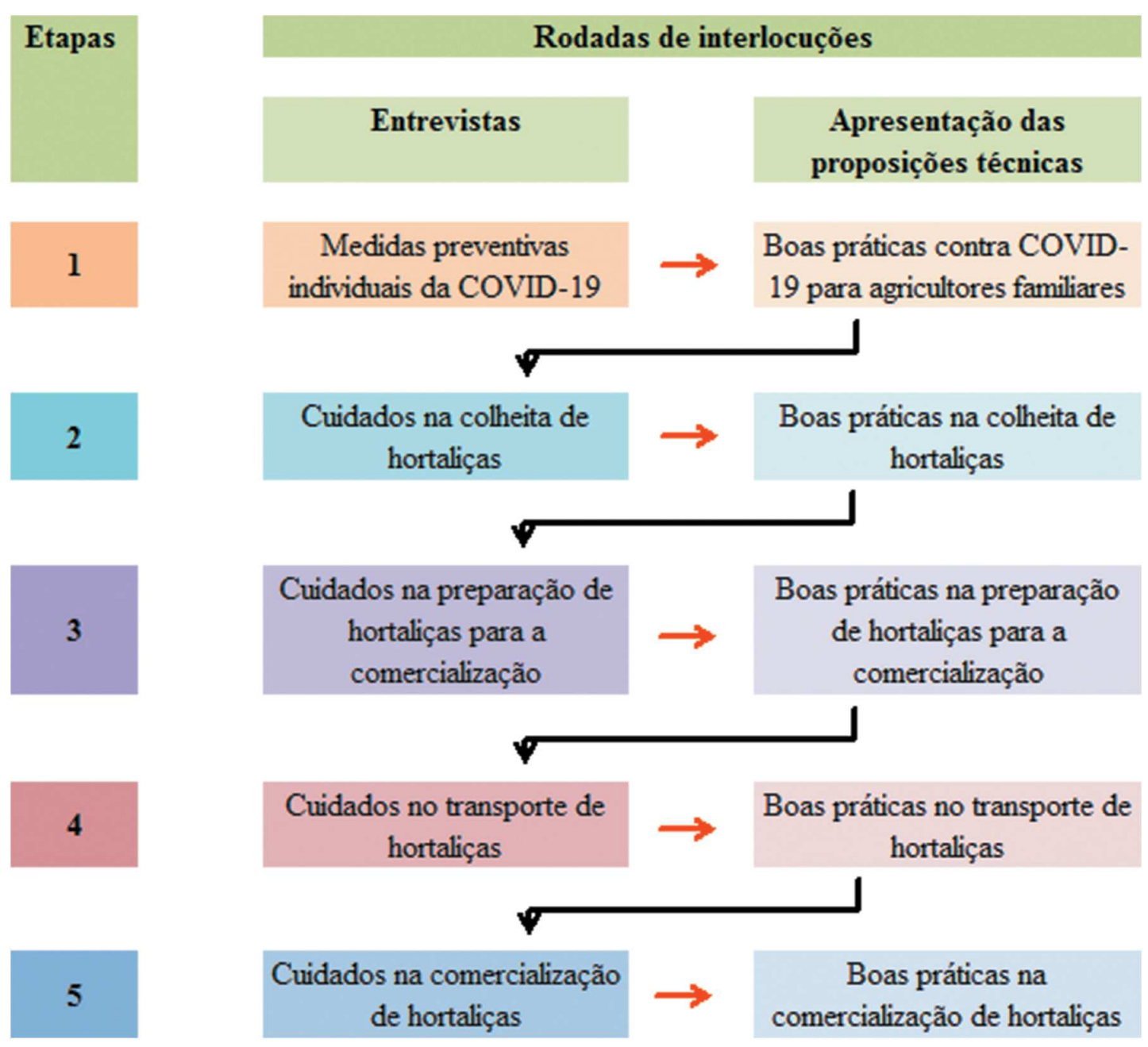

Figura 1: Fluxograma de aplicação dos instrumentos metodológicos aos agricultores familiares, no âmbito da ACE "Manipulação segura de hortaliças". Manaus, 2020.

Fonte: Dados da ACE. 
Após a preparação da equipe, foram iniciadas as interlocuções com os agricultores familiares, sendo que cada discente ficou responsável por um núcleo familiar, visando evitar excesso de mensagens, mensagens repetidas e perdas de informações, garantindo o acompanhamento sistemático e exclusivo de cada família. Assim, nas semanas seguintes, foram realizadas as atividades de verificação das medidas preventivas individuais da COVID19 e dos cuidados nas atividades laborais de manipulação de hortaliças, adotados pelos agricultores familiares, utilizando roteiros de entrevistas estruturadas (GIL, 2007), compostos por questões abertas.

As transcrições das mensagens recebidas foram feitas pelos discentes e enviadas ao professor, por email. Os resultados das entrevistas apenas direcionaram a condução das atividades e, portanto, não foram divulgados. Posteriormente, a partir de bibliografia especializada, foram elaboradas proposições técnicas e apresentadas aos agricultores familiares, por meio de mensagens de texto, chamadas de voz e ligações telefônicas. As proposições também foram redigidas e organizadas em informativos, que foram enviados no formato PDFe estão disponíveis no site https://www.fca.ufam.edu.br/destaque/544-discentes-do-curso-de-agronomia-elaboramcartilhas-para-agricultores-familiares.

O recurso financeiro, disponibilizado à ACE, possibilitou a compra de materiais de prevenção da COVID19, para doação aos agricultores familiares, como: luvas, avental, máscara semifacial, protetor facial, álcool 70\% (líquido e gel) e pulverizador de pressão. O kit foi acompanhado de texto impresso contendo sugestão de utilização de cada item, bem como recomendação de leitura das instruções dos fabricantes dos produtos, antes do uso.

A avaliação da ACE foi contínua, ocorrendo durante as reuniões semanais da equipe. Os discentes mostraram comprometimento e engajamento na execução das atividades, notadamente na elaboração e aplicação dos instrumentos metodológicos, o que proporcionou novas experiências de aprendizagem e troca de saberes com os agricultores familiares. As ações extensionistas auxiliam na formação profissional de discentes, ampliando o seu desenvolvimento intelectual e criativo, estimulando a responsabilidade social e os valores de cidadania, e possibilitando o contato com problemas vivenciados pela sociedade (DINIZ et al., 2020; WOLTMANN et al., 2021).

Na realização das atividades da ACE, a dificuldade encontrada foi contatar os comunitários. Mesmo via celular, pelo aplicativo WhatsApp, os contatos com os agricultores familiares ocorreram tardiamente. Contudo, esse atraso propiciou um período maior de preparação e embasamento teórico mais consistente da equipe.

Em tempos de pandemia, a privação da integração social oportunizou a flexibilização na execução de ações de extensão e a vivência de novas experiências, com o uso de tecnologias de informação e comunicação e mídias digitais (MELO et al., 2020). Mas, as dificuldades no acesso e no uso dessas tecnologias ainda representam limitações para parte significativa da população brasileira.

As estratégias (tecnologias de informação e comunicação e mídias digitais, reuniões semanais, divisão de tarefas, interlocução exclusiva entre discente e núcleo familiar, e sequência das interlocuções) e os instrumentos 
metodológicos (roteiros de entrevistas e informativos) foram determinantes à execução e ao alcance dos objetivos da ACE. Isso pode ser constatado por meio da avaliação feita pelos agricultores familiares e enviada à equipe por seu representante:

\begin{abstract}
Venho em nome de todos os agricultores que receberam orientação técnica e assessoria para comercializar a produção agrícola em tempo de pandemia - dizer que a estratégias e dinâmicas usado nas atividades, trouxe um resultado muito positivo em nossos trabalhos, assim também na nossa organização. Em avaliação com todos os participantes chegamos à conclusão de quê não houve pontos negativos; o trabalho foi excelente e nos trouxe maior clareza e conhecimentos dos cuidados que devemos ter com os produtos - (seleção, colheita, armazenagem, transporte e comercialização) (J.R.P., 62 anos, Comunidade do Uberê, Manaus, AM, 2020).
\end{abstract}

A extensão universitária foi readequada e flexibilizada às necessidades desencadeadas pela pandemia da COVID-19 e ações de enfrentamento foram desenvolvidas para amenizar os impactos da pandemia (MÉLO et al., 2021). Antes, as ferramentas digitais integravam uma das estratégias para o desenvolvimento das ações de extensão; agora, tornaram-se o principal meio para mobilização e articulação entre universidade e sociedade, e ampliação do alcance das ações de extensão (SERRÃO, 2020). No mundo pós-pandemia, a nova realidade trará novas tendências e a extensão universitária terá que continuar se adequando, para continuar contribuindo com a sociedade.

\title{
CONCLUSÕES
}

As estratégias e os instrumentos metodológicos foram determinantes à execução e ao alcance dos objetivos da ação curricular de extensão. No entanto, as dificuldades no acesso e no uso dessas tecnologias ainda representam limitações para muitos agricultores familiares.

\section{AGRADECIMENTOS}

O autor agradece à Pró-Reitoria de Extensão (PROEXT) da Universidade Federal do Amazonas (UFAM) pelo apoio financeiro à ACE “Manipulação segura de hortaliças”, no âmbito do Edital Simplificado No 001/2020 PROEXT/DPROEX. Agradece também aos discentes do Curso de Agronomia da UFAM e aos agricultores familiares da Comunidade do Uberê, pela atenção e disponibilidade, ao participarem da ação curricular de extensão.

\section{REFERÊNCIAS}

DINIZ, Emily Gabriele Marques; SILVA, Adriana Maria; NUNES, Paulo Henrique Valença; FRANCA, Wilza Wanessa Melo; ROCHA, João Victor Ritinto; SILVA, Débora Verônica Sarmento Pereira; SANTOS, Victor Hugo Barbosa; ARAÚJO, Hallysson Douglas Andrade; ALBUQUERQUE, Mônica Camelo Pessoa de Azevedo; AIRES, André de Lima. A extensão universitária frente ao isolamento social imposto pela COVID-19. Brazilian Journal of Development, v. 6, n. 9, p. 72999-73010, set. 2020. Disponível em: <https://doi.org/10.34117/bjdv6n9-669>. Acesso em: 14 Jun. 2021. 
GASPAR, Emanuelle Baldo; DOMINGUES, Robert; BARBOSA, Rosângela Silveira. Recomendações para prevenção da COVID-19 no meio rural na região Sul do Brasil. Bagé: Embrapa Pecuária Sul, Comunicado Técnico, 2020.13 p. Disponível em: <https://www.embrapa.br/busca-de-publicacoes/-/ publicacao/1123196/recomendacoes-para-prevencao-da-covid-19-no-meio-rural-na-regiao-sul-dobrasil>. Acesso em: 1 Set. 2020.

GIL, Antônio Carlos. Métodos e técnicas de pesquisa social. 5. ed. São Paulo: Atlas, 2007. 206 p.

GREGÓRIO, Débora de Souza; MORAES, Gabrielle Ferrante Alves; NASSIF, Jéssica Maida; ALVES, Mayara Rhaíssa de Moraes; CARMO, Nadiele Esteves; JARROUGE, Márcio Georges; BOUÇAS, Rodrigo Ippolito; SANTOS; Ana Cristina Cestari; BOUÇAS, Thais Ruegger Jarrouge. Estudo da contaminação por parasitas em hortaliças da região leste de São Paulo. Science in Health, v. 3, n. 2, p. 96-103, mai./ago. 2012. Disponível em: <http://arquivos.cruzeirodosuleducacional.edu.br /principal/new/revista_scienceinhealth/08_maio_ago_2012/science_02_2012.pdf\#page=40>. Acesso em: 1 Set. 2020.

MAROUELLI, Waldir Aparecido; SILVA, Henoque Ribeiro da. Aspectos sanitários da água para fins de irrigação. Brasília: Embrapa/CNPH, Comunicado Técnico 5, 1998. 7 p. Disponível em: <https:// www.embrapa.br/busca-de-publicacoes/-/publicacao/761884/aspectos-sanitarios-da-agua-para-fins-deirrigacao>. Acesso em: 1 Set. 2020.

MÉLO, Cláudia Batista; FARIAS, Gabrieli Duarte; NUNES, Vitória Régia Rolim; ANDRADE, Tifany Shela Albuquerque Borba; PIAGGE, Carmem Silvia Laureano Dalle. A extensão universitária no Brasil e seus desafios durante a pandemia da COVID-19. Research, Society and Development, v. 10, n. 3, e1210312991, mar. 2021. Disponível em: <http://dx.doi.org/10.33448/rsd-v10i3.12991>. Acesso em: 14 Jun. 2021.

MELO, Juliana Almeida Coelho; SILVA, Charlene; ALVES, Marina Luna de Souza; MACHADO, Isabelle de Souza; LAURINDO, Milena; FIN, Ana Paula Chaise. Extensão universitária na pandemia de COVID-19: Projeto Radiologia na Comunidade, o uso da rede social e ambiente virtual de aprendizagem. Saberes Plurais: Educação na Saúde, v. 4, n. 2, p. 49-60, ago./dez. 2020. Disponível em: <https://seer.ufrgs.br/saberesplurais/article/view/108759>. Acesso em: 14 Jun. 2021.

SERRÃO, Andréa Cristina Pereira. Em tempos de exceção como fazer extensão? Reflexões sobre a prática da extensão universitária no combate à COVID-19. Revista Práticas em Extensão, v. 4, n. 1, p. 47-49, jun. 2020. Disponível em: <https://www.uema.br/2020/06/artigo-em-tempos-de-excecaocomo-fazer-extensao-reflexoes-sobre-a-pratica-da-extensao-universitaria-no-combate-a-covid-19/> . Acesso em: 14 Jun. 2021.

THIOLLENT, Michel. Metodologia da pesquisa-ação. 18. ed. São Paulo: Cortez, 2011. 136 p.

UNIVERSIDADE FEDERAL DO AMAZONAS. Modalidades de extensão. Pró-Reitora de Extensão PROEXT/UFAM. Disponível em: <https://proext.ufam.edu.br/modalidades-de-extensao.html >. Acesso em: 14 Jun. 2021. 
WOLTMANN, Angelita; SILVA, Ana Luiza Almeida; SUBELDIA, Carla Fernanda Gomes; ROCHA, Cristiane Born Cerentini; LINHARES, Eva Luíza Speck de Almeida; SANTOS, Stéfany Medeiros. O extensionista em tempos de pandemia: relato de experiência da extensão em direito realizada por meio do canal virtual do Instagram @ coronajur_ufn. Expressa Extensão, v. 26, n. 1, p. 537-550, jan./abr. 2021. Disponível em: < https://periodicos.ufpel.edu.br/ojs2/index.php/expressaextensao/article/view/ $19636>$ >. Acesso em: 14 Jun. 2021.

Submetido em: 28/06/2021 Aceito em: 04/08/2021. 